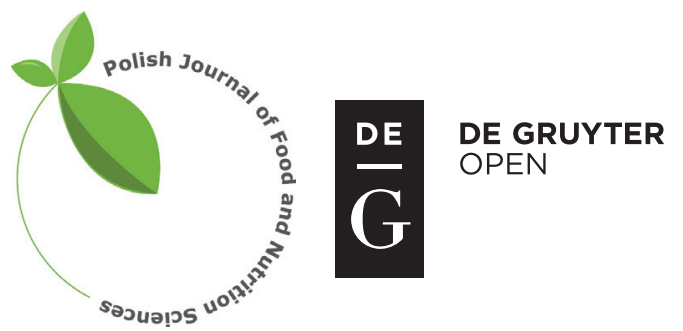

Pol. J. Food Nutr. Sci., 2016, Vol. 66, No. 4, pp. 243-251

DOI: $10.1515 /$ pjfns-2015-0011 http://journal.pan.olsztyn.pl

Review article

Section: Food Technology

\title{
Effect of High Hydrostatic Pressure Processing Strategies on Retention of Antioxidant Phenolic Bioactives in Foods and Beverages - a Review
}

\author{
Özlem Tokuşoğlu \\ Department of Food Engineering, Celal Bayar University, Engineering Faculty, 45140, Manisa, Turkey
}

Key words: high hydrostatic pressure, phenolics, bioactives, foods

Phenolic compounds, especially flavonoids have health-promoting benefits that play some important roles in foods as visual appearance, taste, aroma and represent an abundant antioxidant component of the human and animal diet. High hydrostatic pressure processing (HHPP) conditions (300-700 MPa) at moderate initial temperatures (around ambient) are generally sufficient to inactivate vegetative pathogens for pasteurization processes, some enzymes, or spoilage organisms to extend the shelf-life. The aim of the review is to reveal the effect of high hydrostatic pressure processing strategies on the retention of antioxidant phenolic bioactives in foods and beverages. HHPP can increase extraction capacity of phenolic constituents, and ensure higher levels of preserved bioactive constituents. High pressure extraction (HPE) can shorten processing times, provide higher extraction yields while having less negative effects on the structure and antioxidant activity of bioactive constituents. HPE enhances mass transfer rates, increases cell permeability, increases diffusion of phenolics and retains higher levels of bioactive compounds. Total phenolics in HHPP-treated foods were either unaffected or actually increased in concentration and/or extractability following treatment with high pressure.

\section{INTRODUCTION}

Phenolic compounds are naturally-derived bioactive substances that have health-promoting, and/or nutraceutical and medicinal properties. Phenolics occur as plant secondary metabolites that are widely distributed in the plant kingdom and represent an abundant antioxidant component of the human diet.

Recently, there is a great demand on high quality and convenient products with natural flavor and taste, and fresh appearance of minimally processed food is greatly appreciated. High hydrostatic pressure processing (HHPP) is a non-thermal processing method and holds promise for retaining wholesomeness and freshness of the processed food products. HPP is an emerging technology that can be used instead of thermal process for pasteurization and sterilization. Recent work provides studies to illustrate the ability of this non-thermal food preservation technology regarding the preservation of the phenolic bioactives of plant foods and health-related compounds [Tokuşoğlu \& Swanson, 2015].

ANTIOXIDANT PHENOLICS AS BIOACTIVE
COMPOUNDS

Antioxidant phenolic compounds occur as plant secondary metabolites. Their ubiquitous presence in plants and plant foods favors animal consumption and accumulation in tis-

\footnotetext{
* Corresponding Author: E-mail: tokusogluozlem@yahoo.com health-promoting benefits [Tomas-Barberan \& Espin, 2001].

sues. Polyphenols are widely distributed in the plant kingdom and represent an abundant antioxidant component of the human diet. Interest in the possible health benefits of polyphenols has increased due to the corresponding antioxidant capacities.

Recent evidences show that there is a great interest in anticarcinogenic effects of polyphenolic compounds, as well as the potential to prevent cardiovascular and cerebrovascular diseases. As the name suggests, phytochemicals working together with chemical nutrients found in fruits, cereals, and nuts may help slow the aging process and reduce the risk of many diseases, including cancer, heart disease, stroke, high blood pressure, cataracts, osteoporosis, and urinary tract infections [Meskin et al., 2003; Cheynier, 2005; Tokusoglu \& Hall, 2011].

Polyphenols are divided into several subgroups including flavonoids, hydroxybenzoic and hydroxycinnamic acids, lignans, stilbens, tannins, and coumarins that have specific physiological and biological effects [Andersen \& Markham, 2006; Meskin et al., 2003; Tokuşoğlu, 2001].

Flavonoids are the major group of polyphenols that include flavan-3-ols, flavonols, flavones, flavanones, isoflavones, anthocyanidins, anthocyanins, flavononols, and chalcons as subgroups, that are distributed in plants and food of plant origin [Crozier et al., 2006; Tokusoglu \& Hall, 2011].

Phenolic compounds including flavonoids play some important roles in fruits such as in their visual appearance, taste and aroma. In addition to these, phenolic compounds have 
These bioactive compounds have been found to be important in the quality of plant-derived foods [Tomas-Barberan \& Espin, 2001]. Anthocyanins are type of phenolic compounds classified under flavonoids group of phenolic compounds, which are water-soluble glycosides of anthocyanidins [Kong et al., 2003; Tokuşoğlu \& Yildırım, 2012].

Phenolic contents of the fruits obviously vary from fruits to fruits. This difference may depend on the methods used both for the extraction of the phenolic compounds and methods of analysis. Also, the phenolic compound composition in fruits is affected by some intrinsic factors, such as using different genus, species or cultivars, and extrinsic factors, such as the time of the collection of fruits, location, environmental factors and storage. In addition to these intrinsic and extrinsic factors, some food-processing technologies can also affect the composition of plant phenolics [Tokuşoğlu, 2001].

The aim of this review is to reveal the effect of high hydrostatic pressure processing (HHPP) strategies on the retention of antioxidant phenolic bioactives in foods and beverages.

HIGH PRESSURE PROCESSING (HHP) AND ITS
PREFERENCES AND ADVANTAGES

Phenolic compounds in fruits and vegetables decrease by conventional and traditional heat treatment processes. These thermal treatments are the most used methods to extend the shelf-life of foods by the microorganism and enzyme inactivation while heat causes irreversible losses of nutritional compounds, undesirable alterations in physicochemical properties, and changes of their antioxidant properties [Wang $\& \mathrm{Xu}, 2007$; Plaza et al., 2006].

Many factors including temperature, $\mathrm{pH}$, oxygen, enzymes in the presence of co-pigments, metallic ions, ascorbic acid, sulfur dioxide as well as sugars may affect the stability of the anthocyanins. During pasteurization and storage, several red fruit derivatives lose their bright red colors and become dull red colors. Similarly, the polyphenol content decreases in several liquid, semi-solid or solid foodstuffs by heat treatments [Ferrari et al., 2011]. Many food manufacturers have investigated alternative techniques to thermal pasteurization in order to facilitate the preservation of unstable nutrients and bioactives in foods and beverages.

Non-thermal technologies have been reported to be a good option for obtaining food and beverages with a fresh-like appearance while preserving their nutritional quality [Odriozola-Serrano et al., 2009; Zabetakis et al., 2000]. In that point, the potential use of these emerging technologies, such as 'High Hydrostatic Pressure (HHP)' or 'Pulsed Electrical Fields (PEF)', are important as they inactivate microorganisms and undesirable enzymes to a certain extent and can avoid the negative effects of heat pasteurization [Toepfl et al., 2006].

Recently, there has been an increasing interest for non-thermal technologies as high pressure processing (HPP) to preserve fruits, vegetables, daily foods and beverages. Great technological and research efforts have been made to obtain foods and beverages by HPP without the quality and nutritional damage caused by heat treatments. High hydrostatic pressure or ultrahigh-pressure processing or HPP is one tech- nology that has begun to fulfill its potential to satisfy both consumer and scientific requirements, and it is a leading alternative in replacing thermal processing in some food applications in the drive to meet increasing consumer demand for foods featuring improved organoleptic qualities and higher acceptance [Patterson et al., 2008; Tokuşoğlu \& Doona, 2011a].

High pressure processing (HPP) can be used to obtain a high quality food/beverage and increase its shelf-life while maintaining its physicochemical, nutritional characteristics and bioactive profiles [Tokuşoğlu \&Swanson, 2015; Tokuşoğlu, 2011, 2012a,b; Tokuşoğlu \& Doona, 2011a,b; Tokuşoğlu et al., 2010a].

This technology is especially beneficial for heat sensitive products [Barbosa-Cánovas et al., 2005; Tokusoglu \& Doona, $2011 \mathrm{a}, \mathrm{b}]$.

HPP can be conducted at ambient or moderate temperatures, thereby eliminating thermally-induced cooked offflavors. Compared to thermal processing, the HPP of foods results in products with a fresher taste, better appearance, and texture. Foods are processed in batch (for solid products) or continuous and semi-continuous systems (for liquid products) in a pressure range of 50-1000 $\mathrm{MPa}$; process temperature during pressure treatment can be from below 0 to above $100^{\circ} \mathrm{C}$, while exposure time usually ranges from seconds to 20 min [Corbo et al., 2009; Bevilacqua et al., 2010; Patterson et al., 2008].

High pressure processing (HPP) technology has been successfully applied in several industrial sectors such as meat, seafood, dairy food, fruit juices, fruit and vegetable products. High pressure processing has been found to inactivate several microorganisms and enzymes. However, it has less effect on low molecular weight food components such as vitamins, pigments, flavouring agents and other nutritional compounds. HPP conditions in the range of 300 to $700 \mathrm{MPa}$ at moderate initial temperatures (around ambient) are generally sufficient to inactivate vegetative pathogens for pasteurization processes, some enzymes, or spoilage organisms to extend shelf-life. HPP can also be increased the extraction capacity of phenolic constituents, and higher levels of bioactive compounds are preserved in HPP-treated samples [Tokusoglu \& Doona, 2011a,b].

Consumer perception of food quality depends not only on microbial quality, but also on other food factors such as biochemical and enzymatic reactions and structural changes. In this context, HPP can have an effect on food yield and on sensory qualities such as food color and texture. High pressures can also be used to enhance extraction of compounds from foods. Recent studies have shown that high pressure extraction (HPE) can shorten processing times, and provide higher extraction yields while having less negative effects on the structure and antioxidant activity of bioactive constituents. The use of HPE enhances mass transfer rates, increases cell permeability, and increases diffusion of secondary metabolites [Dornenburg \& Knorr, 1993; Cheftel, 1995; Tokusoglu \& Doona, $2011 \mathrm{a}, \mathrm{b}]$.

HHP increases the dissolution rate of the bioactives. A rapid permeation is observed under HPE owing to the large differential pressure between the cell interior and the exte- 
rior of cell membranes [Zhang et al., 2005]. This situation increases the solvent penetration through the broken membranes into cells or increases the mass transfer rate due to increased permeability [Shouqin et al., 2004].

This means the higher the hydrostatic pressure is, the more solvent can enter into the cell. The more compounds can permeate the cell membrane which could cause the higher yield of extraction [Zhang et al., 2005; Shouqin et al., 2004]. In other words, the extraction capacity of phenolic constituents has been increased by HHP and HPP-treated samples retain higher levels of bioactive compounds Studies on high-pressure preservation effects on total phenolics determined that these compounds were either unaffected or actually increased in concentration and/or extractability following treatment with high pressure [Zhang et al., 2005; Corrales et al., 2008; Prasad et al., 2009ab; Tokuşoğlu et al., 2010b].

\section{HHPP APPLICATIONS ON PHENOLIC AND ANTIOXIDANT BIOACTIVES OF VEGETABLES}

In one study reported by Vazquez-Gutierrez et al. [2013], HHPP (100-600 MPa/1-3 $\mathrm{min} / 25^{\circ} \mathrm{C}$ ) affected the microstructure and antioxidant properties of onions (cv. Doux). Owing to the fact that onions have antioxidant properties and are an important source of bioactive compounds such as phenols, HHP also affected the extractability of potential health-related compounds of the studied onions [Vazquez-Gutierrez et al., 2013].

In this study, it is shown that vitamin $\mathrm{C}$ (ascorbic acid) did not show significant alterations, while the extracted phenolic content and antioxidant activity increased at pressures of 300 or $600 \mathrm{MPa}$ of HHP. Vazquez-Gutierrez et al. [2013] concluded that HHP produced changes in membrane permeability and disruption of cell walls favoring the phenolic compounds releasing from tissue and, in consequence, improving their extractability [Vazquez-Gutierrez et al., 2013].

Jung et al. [2013] stated the potential effectiveness of HHPP on the alterations in quality-related properties of carrot and spinach. In the study described by Jung et al. [2013], better retention of ascorbic acid and carotenoids was observed in carrots and spinaches treated at 100, 300, and $500 \mathrm{MPa}$ for $20 \mathrm{~min}$ compared to the thermal processing [Jung et al., 2013]. It was shown that the flavonoid amounts were increased with increasing pressure levels, leading to the enhanced antioxidant activity and also it was determined that the residual polyphenoloxidase (PPO) activities were decreased in carrot and spinach as $6.9-15.1 \%$ and $21.3-31.1 \%$, respectively. Jung et al. [2013], reported that HHP could be used as an alternative technology for improving the quality of vegetables [Jung et al., 2013].

HHPP (400 MPa/10 min, $500 \mathrm{MPa} / 5 \mathrm{~min}$, $600 \mathrm{MPa} / 2.5 \mathrm{~min}$ ) and high temperature short time (HTST) $\left(110^{\circ} \mathrm{C} / 8.6 \mathrm{~s}\right)$ processing of purple sweet potato nectar was reported by Wang et al. [2012]. The quality-related aspects including the microorganism level, total phenolics, anthocyanins, antioxidant capacity, color and shelf-life prediction during 12 weeks of storage at $4^{\circ} \mathrm{C}$ and $25^{\circ} \mathrm{C}$ were determined. It was reported that the purple sweet potato nectar samples stored at $4^{\circ} \mathrm{C}$ showed better quality and longer shelf-life when compared with those stored at $25^{\circ} \mathrm{C}$, and longer shelf-life was observed in HHP-treated samples compared to HTST-treated ones [Wang et al., 2012].

The shelf-life, estimated in accordance with the zeroorder reaction, was 29.256, 35.862, 32.821 and 32.499 weeks for HTST, $400 \mathrm{MPa} / 10 \mathrm{~min}, 500 \mathrm{MPa} / 5 \mathrm{~min}$, and $600 \mathrm{MPa} / 2.5 \mathrm{~min}$ treated purple sweet potato nectar stored at $4^{\circ} \mathrm{C}$, respectively. By comparison, it was 6.343, 7.256, 8.466 and 7.951 weeks for HTST, $400 \mathrm{MPa} / 10 \mathrm{~min}$, $500 \mathrm{MPa} / 5 \mathrm{~min}$, and $600 \mathrm{MPa} / 2.5 \mathrm{~min}$ treated purple sweet potato nectar stored at $25^{\circ} \mathrm{C}$, respectively [Wang et al., 2012].

A study by Wang et al. [2012] shows the changes of antioxidant capacity (DPPH) in purple sweet potato nectar during 12 -week of storage at $4^{\circ} \mathrm{C}(\mathrm{A})$ and $25^{\circ} \mathrm{C}(\mathrm{B})$. It was determined that the DPPH antioxidant capacity decreased by $23.76-26.97 \%$ and $28.27-41.62 \%$ in purple sweet potato nectar at 4 and $25^{\circ} \mathrm{C}$ after the 12 -week storage. The DPPH antioxidant capacity in HTST-treated samples was higher than that in $400 \mathrm{MPa} / 10 \mathrm{~min}$ treated ones, lower than $600 \mathrm{MPa} / 2.5 \mathrm{~min}$ and $500 \mathrm{MPa} / 5 \mathrm{~min}$ treated ones at $25^{\circ} \mathrm{C}$ [Wang et al., 2012]. It was also shown that sweet potato nectar samples stored at $4^{\circ} \mathrm{C}$ had higher DPPH antioxidant capacity than those stored at $25^{\circ} \mathrm{C}$ [Wang et al., 2012].

Low-pressure treatments (100-200 MPa for 10-20 min) on green peppers caused a decrease of $10-15 \%$ of the initial vitamin $\mathrm{C}$, while in red peppers these treatments resulted in a 10-15\% increase in vitamin C [Barrett \& Lloyd, 2012].

Van Eylen et al. [2007] studied the high pressure (600$-800 \mathrm{MPa})$ and temperature $\left(30-60^{\circ} \mathrm{C}\right)$ stabilities of sulforaphane and phenylethyl isothiocyanate in broccoli juice. It was concluded that isothiocyanates are relatively thermolabile and pressure stable. Van Eylen et al. [2007] also stated that myrosinase activity was stabilized by using mild pressure treatments that led to products with increased isothiocyanate content.

\section{HHPP APPLICATIONS ON PHENOLIC AND ANTIOXIDANT BIOACTIVES OF FRUITS}

It has been reported that the anthocyanins of different liquid foods (red-fruit juices) are stable to HHP treatment at moderate temperatures. The nutraceutical and sensorial properties are strictly related to the anthocyanin and polyphenol content in pomegranate juice at room temperature. It was reported that the stability or preservation of bioactive compounds of red-fruit juices are contradictory. The concentration of red-fruit based bioactives decreases with the intensity of the treatment in terms of pressure level and processing time [Ferrari et al., 2010].

Ferrari et al. [2010] reported on the effects of HHP on the polyphenol contents and anthocyanin levels of several red fruit-based products (strawberry and wild strawberry mousses, pomegranate juice). HHP conditions of $500 \mathrm{MPa}$, $50^{\circ} \mathrm{C}, 10 \mathrm{~min}$ and $400 \mathrm{MPa}, 25^{\circ} \mathrm{C}$ and $5 \mathrm{~min}$ were applied for mousse samples (strawberry and wild strawberry mousses) and pomegranate juice samples, respectively. It was found that the HPP treatment at moderate temperatures promoted the extractability of colored pigments and increased the polyphenol levels of fruits [Ferrari et al., 2010]. 
Ferrari et al. [2011] evaluated the polyphenol level of HPtreated strawberry mousse and wild strawberry mousse at fixed storage times under refrigerated conditions $\left(4^{\circ} \mathrm{C}\right)$, as well as the polyphenol content of high pressure-treated samples of pomegranate juice at fixed storage times under refrigerated conditions $\left(4^{\circ} \mathrm{C}\right)$. The results obtained by Ferrari et al. [2010] showed the potentiality of the HPP process for the treatment of products rich in thermolable and nutraceutical compounds.

Barba et al. [2012] reported quality changes of blueberry juice during 56 days of refrigerated storage at $4^{\circ} \mathrm{C}$ after HPP and pulsed electrical field processing. In their study, blueberry juice was processed by high pressure (HP, $\left.600 \mathrm{MPa} / 42^{\circ} \mathrm{C} / 5 \mathrm{~min}\right)$. A lower than $5 \%$ content of ascorbic acid was found compared with the untreated blueberry juices. At the end of refrigerated storage, unprocessed blueberry juices and similarly PEF-treated juices showed 50\% of ascorbic acid losses whereas $31 \%$ losses of ascorbic acid were found for HPP-treated blueberry juices [Barba et al., 2012].

The same authors reported that the ascorbic acid of HPP-treated blueberry juices remained more stable during storage time and HPP preserved the antioxidant activity (21\% losses) more than unprocessed (30\%) juices and PEF-treated (48\%) juices after 56 days of storage at $4^{\circ} \mathrm{C}$ [Barba et al., 2012]. It was concluded that the second conservation treatment such as refrigerated storage has to be coupled with non-thermal technologies and HPP can be a potentially useful unit operation for preserving bioactive compounds in blueberry juices during refrigerated storage [Barba et al., 2012].

Varela-Santos et al. [2012] stated the HHPP (350$-550 \mathrm{MPa}$ for 30, 90 and $150 \mathrm{~s}$ ) effects on microbial, physicochemical quality and biaoctives of pomegranate juices during 35 days of storage at $4^{\circ} \mathrm{C}$. The applied HHP treatments at over $350 \mathrm{MPa}$ for $150 \mathrm{~s}$ resulted in about 4.0 log cycles reduction of microbial load and these treatments were able to extend the microbiological shelf-life of pomegranate juice stored in the above-mentioned conditions. In the study reported by Varela-Santos et al. [2012], the phenolic levels of pomegranate juices showed an increase in the first 3 days and started to decrease after 5 days. It was shown that the phenolics of pomegranate juices reached a steady-state level after 10 days, remaining constant for those treated samples stored at $4^{\circ} \mathrm{C}$, until the end of the study [Varela-Santos et al., 2012]. It was revealed that high hydrostatic pressure had a remarkable effect on the antioxidant activities, IC50, with much lower values when pressure increases therefore a smaller IC50 value was obtained at $500 \mathrm{MPa}$ which corresponds to a higher antioxidant activity. The DPPH scavenging activities of the pomegranate juice expressed as an IC50 value were $11-20 \mathrm{mg} / \mathrm{mL}$ at the starting point. The juice treated at $450 \mathrm{MPa}$ and $550 \mathrm{MPa}$ exhibited the strongest antioxidant capacity $(11-13 \mathrm{mg} / \mathrm{mL})$, followed by the control sample (14 mg/mL). Pérez-Vicente et al. [2004] concluded that the increase of the antioxidant activity in pomegranate juices could be due to the extraction of some of the hydrolysable tannins, present in the fruit rind, and/or was related to the increase in ellagic acid, ellagic structures polymerized into ellagitannins, and/or anthocyanin polymers formed during the storage period of fruit [Pérez-Vicente et al., 2004].
Vázquez-Gutiérrez et al. [2011] showed the effect of HHPP (for $200 \mathrm{MPa}$ and 400MPa treatment during 1, 3, and $6 \mathrm{~min}$ ) on the microstructure of persimmon fruit cv. 'Rojo Brillante' during two different ripening stages, with and without deastringency treatment $\left(95-98 \% \mathrm{CO}_{2}\right)$, and the relationship of this treatment with changes in the location of some bioactive compounds. They reported that HHP treatment produced a significant effect on the persimmon structure by affecting the integrity of cell walls and membranes, and stated that much of the soluble tannins spread outside vacuoles, carotenoid substances were released from the chromoplasts, cell walls were degraded and extractability was affected. It was concluded that the high hydrostatic pressure application induced the precipitation of soluble tannins in "Rojo Brillante" persimmons, that could be related to the loss of astringency [Vázquez-Gutiérrez et al., 2011].

Food matrix and processing parameters are effective on retaining phenolic compounds. The combination with other emerging methods (ultrasound, gamma-irradiation, carbon dioxide, antimicrobial agents) can also help to retain nutritional and health-related characteristics of these compounds. HHP process condition parameters (pressure, temperature and time) are important for phenolic quality and quantity [Tokusoglu \& Doona, 2011a,b; Tokusoglu et al., 2010b].

Qiu et al. [2006] revealed that the highest stability of lycopene (Figure 1) was found in tomato purée when pressurized at $500 \mathrm{MPa}$ and stored at $4 \pm 1^{\circ} \mathrm{C}$, which retained most of the total lycopene content $(6.25 \pm 0.23 \mathrm{mg} / 100 \mathrm{~g})$. When analyzing total lycopene losses in a lycopene standard (as percentage) and total lycopene content in tomato puree (as $\mathrm{mg} / 100 \mathrm{~g}$ ), respectively, as a function of storage time at $4 \pm 1^{\circ} \mathrm{C}$, at six different HHP conditions Qiu et al. [2006] was found that 500 and $600 \mathrm{MPa}$ of pressure led to the highest reduction of lycopene, while $400 \mathrm{MPa}$ could retain the maximal stability of lycopene. It was established that HHP is an alternative preservation method for producing ambient-stable tomato products in terms of lycopene conservation [Qiu et al., 2006].

The caffeic acid increase in tomato juices after 28 days of storage could be directly associated with residual hydroxylase activities, which convert coumaric acid in caffeic acid. It was stated that total phenolics in tomato-based beverages and tomato purées appeared to be relatively resistant to the effect of HP [Patras et al., 2009; Barba et al., 2010].

After HPP treatment of tomato puree at $400 \mathrm{MPa} / 25^{\circ} \mathrm{C} /$ $/ 15$ min, the ascorbic acid (AA) and total AA contents decreased by $40 \%$ and $30 \%$, respectively [Sánchez-Moreno et al., 2006]. Individual carotenoids including $\beta$-carotene, $\beta$-cryptoxanthin, zeaxanthin and lutein with the antioxidant

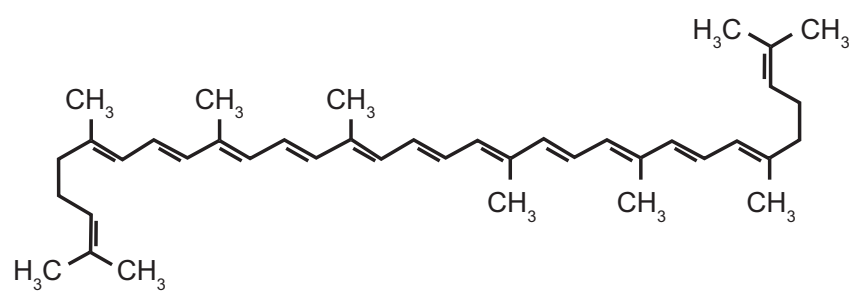

FIGURE 1. Lycopene (adapted from Sigma-Aldrich). 


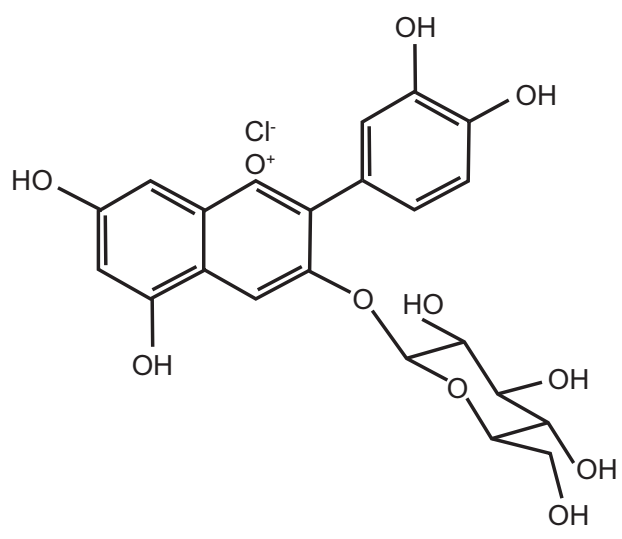

Cyanidin-3-glycoside

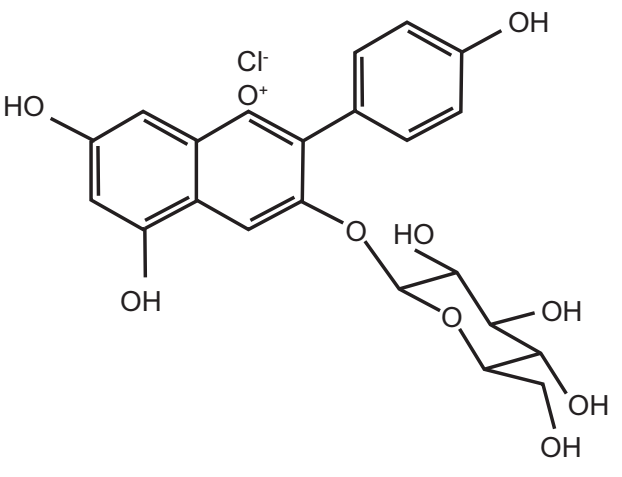

Pelargonidin-3-glycoside

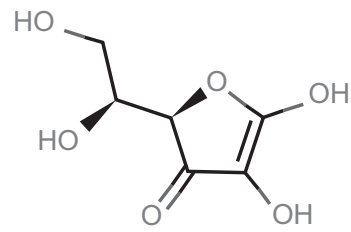

Ascorbic acid

FIGURE 2. Key antioxidants of strawberry and blackberry purées (cyanidin-3-glucoside, pelargonidin-3-glucoside and ascorbic acid).

activity in tomato-based soup appeared to be resistant to a HPP treatment of $400 \mathrm{MPa}$ at $40^{\circ} \mathrm{C}$ for $1 \mathrm{~min}$, thus resulting into a better preservation of the antioxidant activity in comparison with the thermally pasteurized one [Sánchez-Moreno et al., 2005].

Patras et al. [2009] reported contents of key antioxidants (cyanidin-3-glycoside, pelargonidin-3-glucoside, and ascorbic acid) in strawberry and blackberry purées (Figure 2) and quantified their antioxidant activity after various HPP treatments $\left(400,500,600 \mathrm{MPa} / 15 \mathrm{~min} / 10-30^{\circ} \mathrm{C}\right)$ and thermal treatment $\left(70^{\circ} \mathrm{C} / 2 \mathrm{~min}\right)$. They found that the three different pressure treatments did not cause any significant changes in ascorbic acid levels. Following thermal processing $\left(\mathrm{P}_{70} \geq 2 \mathrm{~min}\right)$, the ascorbic acid content degraded by $21 \%$ compared to the unprocessed purée. Similarly, no significant alterations in anthocyanin compounds were observed in HPP-treated and unprocessed purées, while conventional thermal treatments significantly reduced the anthocyanin levels. The antioxidant activity of HPP-treated strawberry and blackberry purées was significantly higher than in the thermally-processed purées [Patras et al., 2009].

It was stated that dry weight content of vitamin $\mathrm{C}$ in strawberry and blackberry purées was significantly higher in HPP-treated samples [Barrett \& Lloyd, 2012]. It was reported that the level of retention of ascorbic acid in guava purée proceeded according to the following decreasing order: (400 MPa for $15 \mathrm{~min})>\left(88-90{ }^{\circ} \mathrm{C}\right.$ for $\left.24 \mathrm{~s}\right)>(600 \mathrm{MPa}$ for $15 \mathrm{~min})$ [Yen \& Lin, 1999].

After HPP processing (400 $\mathrm{MPa}, 40^{\circ} \mathrm{C}, 1 \mathrm{~min}$ ), orange juice presented a significant increase in the extractability of each individual flavanone compared to the untreated juice and hence showed the total flavanone content at $15.46 \%$ [Plaza et al., 2011].

Regarding the main flavanones identified in orange juice, $\mathrm{HP}$ treatments $\left(400 \mathrm{MPa} / 40^{\circ} \mathrm{C} / 1 \mathrm{~min}\right)$ increased the content of naringenin by $20 \%$ and by $40 \%$ the content of hesperetin in comparison with an untreated orange juice [Oms-Oliu et al., 2012a,b]. This data is in accordance with those obtained by other authors showing higher extraction of phenolic compounds and significantly increased levels of phenols due to high pressure processing $\left(600 \mathrm{MPa}, 20^{\circ} \mathrm{C}, 15 \mathrm{~min}\right)$ of strawberry and blackberry purees ( 9.8 and $5.0 \%$, respectively).
The Litchi is the sole member of the genus Litchi in the soapberry family Sapindaceae and it is a tropical fruit tree. The Litchi [Litchi chinensis Sonn.) is a fragranced fruit with a sweet taste. After $30 \mathrm{~min}$ of high pressure extraction (HPE) of Litchi fruit pericarp (LFP), the extract yield, total phenolic level, 1,1-diphenyl-2-picrylhydrazyl radical scavenging activity (DPPH), and superoxide anion scavenging ability were determined [Prasad et al., 2009a]. The extraction yield by treatments of $400 \mathrm{MPa}$ HPE for 30 min was $30 \%$, while that by conventional extraction (CE, control) was $1.83 \%$. There was no significant difference in the total phenolic content (as $\mathrm{mg} / \mathrm{g} \mathrm{DW}$ ) among the two extraction methods (HPE and CE). It was found that the DPPH radical scavenging activity obtained by HPE (400 MPa) was the highest (74\%) [Prasad et al., 2009a].

Epicatechin (EC) and epicatechingallate (ECG) were identified and quantified as the major flavonoids of Litchi, while catechin $(\mathrm{C})$ and procyanidin $\mathrm{B}_{2}$ (Pro $\mathrm{B}_{2}$ ) (Figure 3) were identified as the minor Litchi phenolic compounds [Prasad et al., 2009a]. The total flavonoid content of Litchi was $0.65,0.75,0.29$ and $0.07 \mathrm{mg} / \mathrm{g}$ dry weight by high pressure extraction (HPE) at 200 and $400 \mathrm{MPs}$, ultraextraction (UE), and conventional extraction (CE), respectively. It was reported that the yield of flavonoid extraction increased 2.6 times in comparison with UE, and up to 10 times compared with CE [Prasad et al., 2009a] (Table 3).

The longan fruit ("dragon eyes") (Dimpcarpus longan Lour.) is edible, extremely sweet, juicy and succulent in superior agricultural varieties, and apart from ingested fresh, is also often used in East Asian soups, snacks, desserts, and sweet-and-sour foods, either fresh or dried, sometimes canned with syrup in supermarkets. Prasad et al. [2009b] extracted longan fruit pericarp by various pressures of HPP $\left(200-500 \mathrm{MPa} / 2.5-30 \mathrm{~min}\right.$ at $\left.30^{\circ} \mathrm{C}-70^{\circ} \mathrm{C}\right)$ and by different solvent concentrations $(25-100 \%, \mathrm{v} / \mathrm{v})$ and solid-toliquid ratios $(1: 25-1: 100, \mathrm{w} / \mathrm{v})$. The extraction yield, total phenolics, and scavenging activities of superoxide anion radical and 1,1-diphenyl 1-2-picrylhydrazyl (DPPH) radical by high pressure extraction were determined and compared with those from a conventional extraction for longan fruit pericarp. The HPE provided a higher extraction yield and required a shorter extraction time compared to $\mathrm{CE}$. 
<smiles>Oc1cc(O)c2c(c1)O[C@H](C1=CC(O)C(O)C=C1)[C@H](O)C2</smiles>

Epicatechin (EC)<smiles>CC(c1ccc(O)c(O)c1)C(Cc1c(O)cc(O)cc1Cl)OC(=O)c1cc(O)c(O)c(O)c1</smiles>

Epicatechin Gallate (ECG)

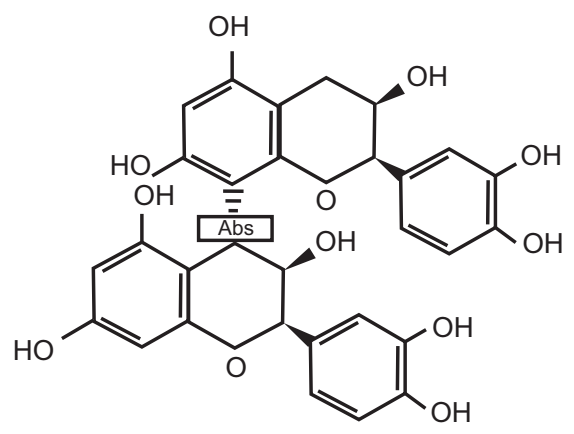

Procyanidin $\mathrm{B}_{2}$

FIGURE 3. Major phenolics in litchi (Litchi chinensis Sonn.) fruit.<smiles>C/C=C1\C(C(=O)OC)=CO[C@H](O[C@H]2O[C@H](CO)[C@@H](O)[C@H](O)[C@H]2O)[C@H]1CC(=O)OCCc1ccc(O)c(O)c1</smiles>

Oleuropein (OLE)<smiles>OCCc1ccc(O)c(O)c1</smiles>

Hydroxytyrosol (HYD)

FIGURE 4. The major phenolics of table olives.

In addition, the total phenolics and the antioxidant activities of HPE were higher than those produced by conventional extraction [Prasad et al., 2009b].

Corrales et al. [2008] examined the extraction capacity of anthocyanins which could be used as natural antioxidants or colorants from grape by-products by HPP and other emerging techniques. The HPP at $600 \mathrm{MPa}$ showed feasibility and selectivity for extraction purposes. The heat treatment effect at $70^{\circ} \mathrm{C}$ combined with the effect of different emerging novel technologies such as ultrasonics $(35 \mathrm{KHz})$, HHPP (600 MPa) and pulsed electric fields (PEF) (3 kV $\mathrm{cm}^{-1}$ ) showed a great feasibility and selectivity for extraction purposes. By one hour of extraction, the total phenolic levels of grape by-products subjected to HHP technology were $50 \%$ higher than in the control samples. With using novel technology applications, the antioxidant activity of the pomace extracts increased with PEF as four-fold, with HHP as three-fold and with ultrasonics as two-fold than in the control extraction [Corrales et al., 2008].

Anthocyanins have been reported to be stable to HP treatments in different fruit juices such as strawberry juice, blackcurrant juice, and raspberry juice [Oms-Oliu et al., 2012 a,b].

Combined pressure and temperature application of blueberry pasteurized juice led to a slightly faster degradation of total anthocyanins during storage compared to conventional heat treatments [Buckow et al., 2010].

Pressure seems to accelerate anthocyanin degradation at elevated temperatures. This can be related to condensation reactions involving covalent association of anthocyanins with other flavanols present in fruit juices.

Tokuşoğlu et al. [2010a] reported that the total phenolics of table olives increased (2.1-2.5)-fold after HPP (as mg gallic acid equivalent/100 g). Phenolic hydroxytyrosol in olives increased on average (0.8-2.0)-fold, whereas phenolic oleuropein decreased on average (1-1.2)-fold after HPP (as mg/ $\mathrm{kg}$ d.w.) (Figure 4). The antioxidant activity values varied from 17.238-29.344 mmol Fe${ }^{2+} / 100 \mathrm{~g}$ for control samples to $18.579-32.998 \mathrm{mmol} \mathrm{Fe}{ }^{2+} / 100 \mathrm{~g}$ for HPP-treated samples [Tokuşoğlu et al., 2010].

High pressure causes a significant reduction in the activity of the enzymes although apparent enzymatic activation of PPO in some HP-treated strawberry samples $\left(300 \mathrm{MPa} / 60^{\circ} \mathrm{C} / 30 \mathrm{~s}\right)$ may be caused by the release of membrane bound enzymes due to pressurization [Terefe et al., 2009].

Vitamin A content of persimmon purée increased as $45 \%$ by high-pressure processing. It was found that the total carotenoid content was significantly higher in all carrot purees treated with high pressure. Following the $600 \mathrm{MPa} / 20^{\circ} \mathrm{C} / 15 \mathrm{~min}$ 
treatment, total carotenoids increased by $58 \%$ as compared to raw carrots. Butz et al. [2002] studied the effects of both high pressure $\left(600 \mathrm{MPa} / 25^{\circ} \mathrm{C}\right)$ or thermal processing $\left(118^{\circ} \mathrm{C} / 20 \mathrm{~min}\right)$ and found that neither preservation method resulted in a significant change in total carotenoids in fruit and vegetable juices, or pieces of apple, peach and tomato.

\section{POTENTIAL OF HHPP}

High hydrostatic pressure processing (HHPP), ultra-high pressure (UHP), ultra-high pressure processing (HPP) are different names and acronyms for equivalent non-thermal processes employing pressures in the range of 200 to $1000 \mathrm{MPa}$ with only small increases in processing temperature. The ultra-high pressures inactivate microbial cells by disrupting membrane systems, retaining the biological activity of quality, sensory and nutrient cell constituents, thus extending the shelf-lives of foods. High pressures inactivate enzymes by altering the secondary and tertiary structures of proteins, changing the functional integrity, biological activity, and susceptibility to proteolysis.

High hydrostatic pressure processing (HHPP) of foods continues with a focus on heat labile acid fruits, vegetables and dairy foods that meet consumer expectations for minimally processing, safety, fresh-like quality and convenience. Non-thermal preservation extends the shelf-life without the addition of preservatives while retains the expected fresh-like appearance, sensory and nutrient quality. It will be necessary to combine non-thermal and thermal preservation technologies to inactivate heat-resistant spores potentially contaminating low-acid foods.

Commercial non-thermal processing success stories such as pasteurized guacamole, oysters, salsa, yogurt and refrigerated meats and improved yields of fruit juices and bioactive compounds from herbs and other plant materials will demonstrate the efficacy and economic success of the technologies in commercial markets. Successful research and identification of economic benefits including energy and water conservation as well as demonstrated safety and fresh-like quality attributes will improve consumer perception of non-thermal technologies and result in further development by the food industry around the world.

\section{CONCLUSION}

High hydrostatic pressure processing is an excellent food processing technology that has the potential to retain the bioactive constituents with health properties in plant foods. The treated foods retain more of their fresh-like features and can be marketed at a premium over their thermally-processed counterparts.

\section{REFERENCES}

1. Andersen Q.M., Markham K.R., Flavonoids. Chemistry, Biochemistry, and Applications. 2006. CRC Press, Taylor \& Francis, Boca Raton, FL. 171-197 p.

2. Barba F.J., Jäger H., Meneses N., Esteve M.J., Frígola A., Knorr D., Evaluation of quality changes of blueberry juice during re- frigerated storage after high-pressure and pulsed electric fields processing. Inn. Food Sci. Em. Technol., 2012, 14, 18-24.

3. Barba F.J., Esteve M.J., Frigola A., Ascorbic acid is the only bioactive that is better preserved by hydrostatic pressure than by thermal treatment of a vegetable beverage. J. Agric. Food Chem., 2010, 58, 10070-10075.

4. Barbosa-Cánovas G.V., Pothakamury U.R., Palou E., Swanson B., Emerging technologies in food preservation. 1998, in: Nonthermal Preservation of Foods (ed. E. Palou). Marcel Dekker, New York, pp. 1-9, 296.

5. Barbosa-Cánovas G.V., Tapia María S., Pilar Cano M., Belloso O.M., Martinez A., Novel Food Processing Technologies. 2005, Marcel Dekker, New York, p. 692.

6. Barrett Diane M., Lloyd B., Advanced preservation methods and nutrient retention in fruits and vegetables. J. Sci. Food Agric., 2012, 92, 7-22.

7. Bevilacqua A., Campaniello D., Sinigaglia M., Use of high pressure processing for food preservation, 2010. Chapter 8, in: Application of Alternative Food-Preservation Techniques to Enhance Food Safety and Stability (eds. A. Bevilacqua, M.R. Corbo, M. Sinigaglia). Bentham Science Publishers Ltd., pp. 114-142.

8. Buckow R., Kastell A., Shiferaw Terefe N., Versteeg C., Pressure and temperature effects on degradation kinetics and storage stability of total anthocyanins in blueberry juice. J. Agric. Food Chem., 2010, 58, 10076-10084.

9. Butz P., Edenharder R., Fernandez Garcia A., Fister H., Merkel C., Tauscher B., Changes in functional properties of vegetables induced by high pressure treatment. Food Res. Int., 2002, 35, 295-300.

10. Cheftel J.C., Review: High pressure, microbial inactivation and food preservation. Food Sci. Technol. Int., 1995, 1, 75-90.

11. Cheynier V., Polyphenols in foods are more complex than often thought. Am. J. Clin. Nutr., 2005, 81, Suppl., 223-229.

12. Corbo M.R., Bevilacqua A., Campaniello D., D'Amato D., Speranza B., Sinigaglia M., Prolonging microbial shelf life of foods through the use of natural compounds and non-thermal approaches. Int. J. Food Sci. Technol., 2009, 44, 223-241.

13. Corrales M., Toepfl S., Butz P., Knorr D., Tauscher B., Extraction of anthocyanins from grape by-products assisted by ultrasonic, high hydrostatic pressure or pulsed electric fields: A comparison. Innov. Food Sci. Emerg. Technol., 2008, 9, 85-91.

14. Crozier A., Jaganath I.B., Clifford M.N., Phenols, polyphenols and tannins: An overview. 2006, in: Plant Secondary Metabolites (eds. A. Crozier, M.N. Clifford, H. Ashihara). Oxford: Blackwell Publishing, Ltd., pp. 1-24.

15. Dornenburg H., Knorr D., Cellular permeabilization of cultured plant tissues by high electric field pulses or ultra high pressure for the recovery of secondary metabolites. Food Biotechnol., 1993, 7, 35-48.

16. Ferrari G., Maresca P., Ciccarone R., The effects of high hydrostatic pressure on the polyphenols and anthocyanins in red fruit products. Procedia Food Sci., 2011, 1, 847-853.

17. Ferrari G., Maresca P., Ciccarone R., The application of high hydrostatic pressure for the stabilization of functional foods: pomegranate juice. J. Food Eng., 2010, 100, 2, 245-53.

18. Kong J.M., Chia L.S., Goh N.K., Chia T.F., Brouillard R., Analysis and biological activities of anthocyanins. Phytochemistry, 2003, 64, 923-933.

19. Jung L.S., Lee S.H., Kim S., Ahn J., Effect of high hydrostatic pressure on the quality-related properties of carrot and spinach. Food Sci. Biotechnol., 2013, 22, 189-195. 
20. Merken H.M., Beecher G.R., Measurement of food flavonoids by high performance liquid chromatography: A review. J. Agric. Food Chem., 2000, 48, 577-599.

21. Meskin M.S., Bidlack W.R., Davies A.J., Lewis D.S., Randolph R.K., Phytochemicals: Mechanisms of Action. 2003 (eds. M.S. Meskin, W.R. Bidlack, A.J. Davies). ISBN:0849316723, ISBN-13: 9780849316722. Boca Raton, FL, CRC Press Taylor and Francis, p. 203.

22. Odriozola-Serrano I., Soliva-Fortuny R., Martin-Belloso O., Impact of high-intensity pulsed electric fields variables on vitamin $\mathrm{C}$, anthocyanins and antioxidant capacity of strawberry juice. LWT - Food Sci. Technol., 2009, 42, 93-100.

23. Oms-Oliu G., Odriozola-Serrano I., Soliva-Fortuny R., Elez-Martinez P., Martin-Belloso O., Stability of health related compounds in plant foods through the application of non thermal processes. Trends Food Sci. Technol., 2012a, 23, 111-123.

24. Oms-Oliu G., Odriozola-Serrano I., Martín-Belloso O., The Effects of Non-Thermal Technologies on Phytochemicals. 2012b, in: Phytochemicals - A Global Perspective of Their Role in Nutrition and Health (ed. Venketeshwer Rao). Chapter 5, ISBN 978-953-51-0296-0, InTech Publishing, pp. 107-126, p. 538.

25. Patras A., Brunton N., Da Pieve S., Butler F., Downey G., Effect of thermal and high pressure processing on antioxidant activity and instrumental colour of tomato and carrot purees. Innov. Food Sci. Emerg. Technol., 2009, 10, 16-22.

26. Patterson M.F., Linton M., Doona C.J., Introduction to High Pressure Processing of Foods. 2008, in: High Pressure Processing of Foods (eds. C.J. Doona, F.E. Feehery). Chapter 1. Wiley-Blackwell Publishing, USA, pp. 29-42.

27. Pérez-Vicente A., Serrano P., Abellán P., García-Viguera C., Influence of packaging material on pomegranate juice colour and bioactive compounds, during storage. J. Sci. Food Agric., 2004, 84, 639-644.

28. Plaza L., Sánchez-Moreno C., De Ancos B., Elez-Martinez P., Martin-Belloso O., Cano M.P., Carotenoid and flavanone content during refrigerated storage of orange juice processed by high-pressure, pulsed electric fields and low pasteurization. LWT - Food Sci. Technol., 2011, 44, 834-839.

29. Plaza L., Sánchez-Moreno C., Elez-Martínez P., de Ancos B., Martín-Belloso O., Cano M. P., Effect of refrigerated storage on vitamin $\mathrm{C}$ and antioxidant activity of orange juice processed by high-pressure or pulsed electric fields with regard to low pasteurization. Eur. Food Res. Technol., 2006, 223, 487-493.

30. Prasad K.N., Yang B., Ruenroengklin N., Jiang Y., Application of ultrasonication or high-pressure extraction of flavonoids from litchi fruit pericarp. J. Food Proc. Eng., 2009a, 32, 828-843.

31. Prasad K.N., Yang E., Yi C., Zhao M., Jiang Y., Effects of high pressure extraction on the extraction yield, total phenolic content and antioxidant activity of longan fruit pericarp. Innov. Food Sci. Emerg. Technol., 2009b, 10, 155-159.

32. Qiu W., Jiang H., Wang H., Gao Y., Effect of high hydrostatic pressure on lycopene stability. Food Chem., 2006, 97, 516-523.

33. Sánchez-Moreno C., Cano M.P., De Ancos B., Plaza L., Olmedilla B., Granado F., Elez-Martínez P., Martín-Belloso O., Martín A., Intake of Mediterranean vegetable soup treated by pulsed electric fields affects plasma vitamin $\mathrm{C}$ and antioxidant biomarkers in humans. Int. J. Food Sci. Nutr., 2005, 56, 115-124.

34. Sánchez-Moreno C., Plaza L., De Ancos B., Cano M.P., Impact of high-pressure and traditional thermal processing of tomato purée on carotenoids, vitamin $\mathrm{C}$ and antioxidant activity. J. Sci. Food Agric., 2006, 86, 171-179.

35. Shouqin Z., Junjie Z., Changzhen W., Novel high pressure extraction technology. Int. J. Pharm., 2004, 278, 471-474.

36. Terefe N.S., Matthies K., Simons L., Versteeg C., Combined high pressure-mild temperature processing for optimal retention of physical and nutritional quality of strawberries (Fragaria $\mathrm{x}$ ananassa). Innov. Food Sci. Emer. Technol., 2009, 10, 297-307.

37. Toepfl S., Mathys A., Heinz V., Knorr D., Review: Potential of high hydrostatic pressure and pulsed electric fields for energy efficient and environmentally friendly food processing. Food Rev. Int., 2006 , 22, 405-423.

38. Tokuşoğlu Ö., Swanson B.G., Improving Food Quality with Novel Food Processing Technologies. 2015. CRC Press, Taylor \& Francis Group, Boca Raton, Florida, USA. ISBN 9781466507241, p. 350 .

39. Tokuşoğlu Ö., ANPFT2012 International Congress-Proceeding Book. Advanced Nonthermal Processing in Food Technology: Effects of Quality and Shelf Life of Food and Beverages. 2012a. (ed. Ö. Tokuşoğlu), 07-10 May, 2012, Kuşadasi Turkey. Celal Bayar University Publishing, Turkey, ISBN: 978-975-8628-33-9, p. 321 .

40. Tokuşoğlu Ö., High Pressure Processing (HPP) strategies on polyphenolic bioactives and shelf life stability in foods and beverages. 2012b, in: Book of Abstracts of the 7th International Conference on High Pressure Bioscience and Biotechnology. Oct.29-Nov.2, 2012, Otsu, Kyoto, Japan, L1-14, Session 2, 1600-1645. p. 40.

41. Tokuşoğlu Ö., Yıldırım Z., Effects of cooking methods on the anthocyanin levels and antioxidant activity of a local Turkish sweet potato (Ipomoea batatas (L.) Lam.) cultivar Hatay Kırmızı: Boiling, steaming and frying effects. Turkish J. Field Crops, 2012, 17, 2, 87-90.

42. Tokuşoğlu Ö., Hall C., Introduction to Bioactives in Fruits and Cereals. 2011, in: Fruit and Cereal Bioactives: Sources, Chemistry \& Applications (eds. Ö. Tokuşoğlu, C. Hall). Chapter 1 - Part I. Introduction, CRC Press, Taylor \& Francis Group, Boca Raton, Florida, USA, ISBN: 9781439806654 ; ISBN-10:1439806659, p. 459.

43. Tokuşoğlu Ö., Doona C.J., High Pressure Processing Technology on Bioactives in Fruits \& Cereals 2011a., in: Fruit and Cereal Bioactives: Sources, Chemistry \& Applications (eds. Ö. Tokuşoğlu, C. Hall). Chapter 21 - Part IV. Functionality, Processing, Characterization and Applications of Fruit \& Cereal Bioactives, CRC Press, Taylor \& Francis Group, Boca Raton, Florida, USA, ISBN: 9781439806654 ; ISBN-10:1439806659, p. 459.

44. Tokuşoğlu Ö., Doona C.J., High Pressure Processing [HHP] Strategies on Food Functionality, Quality and Bioactives: Biochemical and Microbiological Aspects. 2011b, Nonthermal Processing Division Workshop 2011, October 12-14, Osnabrück, Germany.

45. Tokuşoğlu Ö., Effects of High Pressure and Ultrasound on Food Phytochemicals and Quality Improving. 2011, Invited Research Conference, U.S. Army Natick Soldier Res., Development \& Engineering Center, Natick, Massachusetts, MA, USA, June 17, 2011.

46. Tokuşoğlu Ö., Bozoğlu F., Doona C.J., High pressure processing strategies on phytochemicals, bioactives and antioxidant activity in foods. 2010a, in: Book of Abstracts of the 2010 IFT Annual 
Meeting+Food Expo. July 19 2010, Chicago $<$ Illinois, USA, p. 115.

47. Tokuşoğlu Ö., Alpas H., Bozoğlu F.T., High hydrostatic pressure effects on mold flora, citrinin mycotoxin, hydroxytyrosol, oleuropein phenolics and antioxidant activity of black table olives. Innov. Food Sci. Emer. Technol., 2010b, 11, 2, 250-258.

48. Tokuşoğlu Ö., The Determination of the Major Phenolic Compounds (Flavanols, Flavonols, Tannins and Aroma Properties of Black Teas). 2001. PhD Thesis. Department of Food Engineering, Bornova, Izmir, Turkey: Ege University.

49. Tomas-Barberan F., Espin C.J., Phenolic compound and related enzymes as determinants of quality in fruits and vegetables. J. Sci. Food Agric., 2001, 81, 853-876.

50. Van Eylen D., Oey I., Hendrickx M., Van Loey A., Kinetics of the stability of broccoli (Brassica oleracea cv. Italica) myrosinase and isothiocyanates in broccoli juice during pressure/temperature treatments. J. Agric. Food Chem., 2007, 55, 2163-2170.

51. Varela-Santos E., Ochoa-Martinez A., Tabilo-Munizaga G., Reyes J.E., Pérez-Won M., Briones-Labarca V., Morales-Castro J., Effect of high hydrostatic pressure (HHP) processing on physicochemical properties, bioactive compounds and shelf-life of pomegranate juice. Innov. Food Sci. Emer. Technol., 2012, 13, $13-22$.

52. Vázquez-Gutiérrez J.L., Plaza L., Hernando I., Sanchez-Moreno C., Quiles A., de Ancos B., Cano M.P., Changes in the structure and antioxidant properties of onions by high pressure treatment. Food Funct., 2013, 4, 4, 586-591.

53. Vázquez-Gutiérrez J.L., Quiles A., Hernando I., Pérez-Munuera I., Changes in the microstructure and location of some bioactive compounds in persimmons treated by high hydrostatic pressure. Postharv. Biol. Technol., 2011, 61, 137-144.

54. Wang W., Xu S., Degradation kinetics of anthocyanins in blackberry juice and concentrate. J. Food Eng., 2007, 82, 271-275.

55. Wang Y., Liu F., Cao X., Chen F., Hu X., Liao X., Comparison of high hydrostatic pressure and high temperature short time processing on quality of purple sweet potato nectar. Innov. Food Sci. Emer. Technol., 2012, 16, 326-334.

56. Yen G., Lin H.T., Changes in volatile flavor components of guava juice with high-pressure treatment and heat processing and during storage. J. Agric. Food Chem., 1999, 47, 2082-2087.

57. Zabetakis I., Leclerc D., Kajda P., The effect of high hydrostatic pressure on the strawberry anthocyanins. J. Agric. Food Chem., 2000, 48, 2749-2754.

58. Zhang S., Xi J., Wang C., High hydrostatic pressure extraction of flavonoids from propolis. J. Chem. Technol. Biotechnol., 2005, 80, 50-54.

Submitted: 10 March 2014. Revised: 18 September 2014 and 18 April 2016. Accepted: 18 April 2016. Published on-line: 30 August 2016. 
